menos interesante es el par de trabajos dedicados a Vallejo: una síntesis que es in nuce un afortunado «ensayo de biografía literaria». [UUna introducción a César Vallejo»] y un recuento de las tribulaciones de César Vallejo con sus traductores [«La traducción: arte de la frustración»], que desemboca en el análisis de la larga reseña que Giovanni Meo-Zilio hiciera de las versiones de Roberto Paoli (Rassegna Iberistica, v. 2). También Borges recibe dos veces la atención de Gustav Siebenmann: en «Jorge Luis Borges y el enigmático ejercicio de la literatura» se hace descripción de los sistemas valorativos adoptados por Borges, «explícita o implícitamente», como creador de un nuevo tipo de fícción «que revela con gracia la estrategia de su propia escritura», autotélica y a la vez necesitada de complicidad con un lector requerido; tal descripción de sistemas se complementa con las páginas de «Borges y la literatura desrealizada» que hace unidad con ella.

Hay algunas analogías metodológicas entre el estudio dedicado a Cien años... y el que cierra el libro, "Reconsideración de Los de abajo», en que se mide el grado de su contribución al proceso mitificatorio de la revolución mexicana. Mediante la valoración de los cambios sufridos por Los de abajo en sucesivas reescrituras se advierte una reforzada tendencia a la mitificación; las estrategias y artificios narrativos y aun los aparentes «desperfectos» de su texto concurren al mismo fin, son instrumentalizados en su beneficio. Queda una pregunta: ¿a cuál de los opuestos mitos de la Revolución han servido texto y autor en los largos años de escritura que concluyen en 1958, con la edición definitiva?

«La hacienda y la literatura indigenista» y «La serpiente de oro, de Ciro Alegría: novela cholista» completan este excepcional volumen, de cuya lectura se desprende que también su autor, Gustav Siebenmann, es un maître à penser, en el recinto de nuestra profesión.

The City University of New York.

Alberto Blasi

(Brooklyn College \& Graduate School).

Rosalba Campra: América latina: La identidad y la máscara. México: Siglo XXI Editores, 1987.

La preocupación por revelar tanto las diversas identidades de Latinoamérica como esa identidad común, resultado del encuentro y fusión de multiplicidades; el papel que en ello ha desempeñado la literatura; los pasos que ésta emprendiera para crear en Latinoamérica una conciencia de sí (de la que esa literatura es voz privilegiada): modernismo, novelística de la Revolución mexicana, vanguardias poéticas, construcciones narrativas como las de Borges, Asturias y Carpentier en los cuarenta, la culminación de este empeño en la década de los sesenta y en las siguientes... Tales son los motivos recurrentes en este libro, que no se postula, entonces, ni como una historia global de la literatura hispanoamericana, según los modelos en uso, ni como un panorama exhaustivo de autores y tendencias. Más bien quiere ser $-\mathrm{y}$ es«una guía para descifrar una imagen en la que Latinoamérica se busca y se construye a sí misma» (p. 7).

La autora, con penetración y en uso de infinidad de lecturas bien asimiladas $\mathrm{y}$, sobre todo, lúcidamente interrelacionadas, individualiza los «ejes problemáticos» que le permiten definir constantes significativas en el espacio textual de la literatura latinoamericana. Pero, si bien es cierto que el centro medular de sus inquisiciones lo constituye la producción literaria continental, su acercamiento no es hacia una 
circunscrita «literariedad» de ésta, sino más bien al mundo que la produce y exige. Modalidad perfectamente justificada, tanto por la indole misma del objeto que estudia como por el propósito que la anima. Por eso la atención de la estudiosa se dirige a la problemática unidad de América Latina, cuyas raíces acertadamente ve en su condición de entidad histórico-cultural permanentemente agredida por tentativas de anulación. Nuestro continente - se nos recuerda - accede a la unicidad por el yugo colonial que le impone una lengua, una religión y un orden jurídico-social. Viene luego el desgarro que significan la penetración económica británica del xIx y el expansionismo norteamericano de este siglo.

Dependiendo de ese estrato económico-social de base surge la condición colonial en la misma conciencia de ser. Se desenvuelve así, explicablemente, una conducta permanentemente mimética. Ello explica que la nuestra sea una imaginación «controlada», y que su único rostro aceptable lo constituya el de su máscara. Contra tal actitud subordinada se va desarrollando -inicialmente de modo inconsciente, luego de forma muy lúcida- una obra hecha de rechazos. Toma aquí Rosalba Campra las conocidas propuestas de $\mathrm{A}$. Cándido sobre las relaciones entre literatura y subdesarrollo, para encaminarlas hacia una clarificación de lo que ha sido «la huella de la realidad en la literatura latinoamericana». De allí una de las tesis centrales del libro: «Frente a una subalternidad de siglos, hoy Latinoamérica tiende a afirmarse con el ímpetu del postergado que por fin reclama el derecho a decir 'yo'» (p. 19 y passim). Es esta definición - se postula - la que subyace a toda expresión literaria y crítica genuinamente latinoamericana. No es descubrimiento de la ensayista éste de que la necesidad de reconocer y afirmar la propia identidad constituye una clave de nuestra literatura. La propia autora se encarga de recordar algunos de los innumerables estudios sobre el tema: los varios y muy difundidos de Zum Felde, El pecado original de América de Murena, el buen trabajo de síntesis de Abellán titulado La idea de América (Madrid, 1972) y un largo etcétera. La originalidad del aporte está no sólo en la revisión inteligente y actualizada del asunto, sino también en el apoyo documental que proporcionan los textos re-leídos y las valiosas entrevistas que conforman la segunda parte del libro, en que nueve autores contemporáneos -Borges, Bosch, Carpentier, Cortázar, Galeano, Sábato, Scorza, David Viñas y Walsh - responden a las mismas preguntas centrales con las que se ha ido inquiriendo los textos.

En el recorrido histórico a que se someten los títulos más representativos de nuestra literatura (con lamentables exclusiones como los mistralianos, por ejemplo: Tala, Lagar, Poema de Chile) se los agrupa en unos cuantos ejes temáticos, ordenados todos en torno a esa aspiración a una centralidad propia que, como respuesta a la marginalidad, se quiere construir desde la conciencia misma de estar situado en la periferia. El largo proceso tiene en la Revolución cubana - demuestra la autoraun momento de viraje: «Es como si, visible por primera vez para los demás, en cuanto productora de un envidiable fenómeno propio, América Latina resultara también visible para sí misma; finalmente (Rosalba Campra lo dice utilizando la famosa expresión de Paz y Fuentes), se ha vuelto contemporánea del resto del mundo» (p. 22). Con ese evento crucial como nuevo inicio, la literatura comienza a distanciarse significativamente de parámetros axiológicos de matriz europea, abandona su posición de "exótica» para proponer con autenticidad los elementos con que se va configurando el ser latinoamericano. Importa subrayar lo convincente que resulta -en el trabajo de Rosalba Campra- que más allá de las distinciones más o menos obvias entre autores y obras muy disímiles que nos ofrece la literatura latinoamericana contemporánea, ésta muestre una «analogía de actitudes» muy bien detectadas y analizadas por la ensayista. 
No corresponde a una nota informativa como ésta reseñar todos los muchos aportes que, en aspectos concretos, nos entrega en rica síntesis la estudiosa argentina. Conformémonos con enumerar los puntos centrales que ella desarrolla y que, al ser sometidos a penetrante escrutinio, ofrecen una imagen coherente del desenvolvimiento de una literatura. Esta, al no ser enfocada así, suele mostrársenos -en los manuales al uso- desperdigada en nombres y títulos sueltos, sin relación orgánica entre sí o, lo que es quizás más grave, sometida a intentos de agrupación y ordenamientos, que muchas veces, por su mismo excesivo rigor, terminan por ser inoperantes. Aquí no: desde la literatura del indio, del gaucho y el inmigrante (a los que la ensayista denomina «los arquetipos de la marginalidad») hasta la mirada que sobre nuestra literatura dirigen hoy día "los otros», se revisan; las viejas tesis de "civilización y barbarie»; los recientes intentos por llegar a fundaciones míticas en espacios escriturales —Santa María de Onetti, Macondo de García Márquez-; la prolongada certeza de que la nuestra es realidad «maravillosa»; la preferentemente rioplatense inclinación hacia «lo fantástico»; «lo real espantoso» de la violencia institucionalizada en nuestras sociedades y una literatura que la expresa según la especificidad de sus códigos; la historia ya demasiado larga de los sucesivos exilios y st extremo: el de autores «desaparecidos»... Repito: el mérito grande del estudio está no sólo en la re-lectura actualizada a que se someten viejos y recientes temas que han preocupado a la crítica de la literatura latinoamericana, sino en la visión coherente que del desarrollo de ésta logra proporcionársenos. Quede claro, entonces, que este ensayo no es uno más entre los que la avalancha editorial de los últimos años nos ha sometido, sino un título de esos que sí resulta legítimo calificar de «imprescindibles».

\section{Drew University.}

Marcelo Coddou

José Promis: La identidad de Hispanoamérica. Ensayo sobre literatura colonial. México: Universidad de Guadalajara, 1987.

Motivo de congratulación para todos los interesados es que en los últimos plazos comiencen a multiplicarse los estudios historiográficos que se extienden a otras instancias de la producción literaria de Hispanoamérica que no sea la de la novela actual y la lírica de vanguardia. Así, un período tan decisivo en la conformación de la cultura continental, el de la Conquista y la Colonia, es objeto de consideraciones renovadas y renovadoras por parte de investigadores informados y rigurosos. Menciono tres que son de compatriotas del autor del libro que reseñamos: el primer tomo de la Historia de la literatura hispanoamericana de Cedomil Goić; el inteligente y polémico libro de Hernán Vidal Socio-historia de la literatura colonial hispanoamericana: Tres lecturas orgánicas, y el sugerente escrito de Leónidas Emilfork La conquista de México. Ensayo de poética americana. Obras de muy diverso -y hasta contradictorio- carácter tienen en común, no obstante, no tan sólo el tema que revisan, sino la modalidad ensayística de aproximación. En todos ellos las proposiciones son eminentemente críticas e interpretativas. Esta actitud prima sobre el mero intento de recopilar datos (fechas, títulos, acontecimientos), para, sobre todo, ofrecer de ellos una lectura orgánica.

$\mathrm{Y}$ es precisamente de «ensayo» como Promis subtitula su trabajo. Al igual que en los otros tres recordados, hay un propósito de re-descubrir, de poner bajo nueva luz. hechos conocidos. Por ejemplo: se sabe de los intentos por hacer operantes en la 